\title{
Changes in the myoelectrical activity during electrical stimulation of healthy and mastitis-changed mammary glands in dairy cows
}

\author{
Albert Czerski1 ${ }^{1}$, Milan Vasil ${ }^{2}$, Juraj Elečko², Zuzana Farkašová2, František Zigo², \\ Tomasz Walski ${ }^{4}$, Wojciech Zawadzki ${ }^{1}$, Jan Gnus ${ }^{3}$, Maciej Janeczek ${ }^{1}$, Aleksander Chroszcz ${ }^{1}$ \\ ${ }^{1}$ Wroclaw University of Environmental and Life Sciences, Institute of Animal Physiology, \\ Department of Animal Physiology and Biostructure, Poland \\ ${ }^{2}$ University of Veterinary Medicine and Pharmacy in Košice, Institute of Animal Breeding, \\ Department of Nutrition, Dietetics and Animal Breeding, Slovak Republic \\ ${ }^{3}$ Provincial Specialized Hospital, Research and Development Center in Wroclaw, \\ General and Vascular Surgery Ward, Poland \\ ${ }^{4}$ Wrocław University of Technology, Institute of Biomedical Engineering and Instrumentation, \\ Regional Specialist Hospital in Wroclaw, Research and Development Centre, Poland
}

Received October 7, 2013

Accepted April 24, 2014

\begin{abstract}
The aim of this study was to develop a new method of mastitis diagnosis. The study was carried out on 14 highly productive dairy cows of Holstein-Friesian breed. The animals were divided into two groups. The first clinical group consisted of 7 animals with confirmed mastitis. The second control group consisted of 7 mastitis-free animals. Mastitis was confirmed by clinical examination, California Mastitis Test, and bacteriological examination of the milk. The recording of spontaneous myoelectrical activity of the udder was followed by the registration of the voltage of the electrical current passed through the udder using EMS (electrical muscle stimulator). An increase of $540 \%$ in the amplitude of spontaneous spike potentials recorded in the mastitischanged udder compared to the healthy udder was noted. Simultaneously, a decrease of $54 \%$ in the voltage of current generated by the electrical muscle stimulator passed through the mastitischanged udder compared to the healthy udder was observed. The method of diagnosing mastitis in dairy cows shown in this study can be an alternative to California Mastitis Test because of its simplicity, velocity and inexpensiveness.
\end{abstract}

Electrical resistivity, conductivity, udder examination, mastitis, inflammation

Animal and human tissues have the ability to conduct electrical signals. Study of the bioelectricity can be helpful to understand the development, regeneration and variety of pathological processes of cells (McCaig et al. 2005; McCaig et al. 2009). Evidence suggests that induced tissue inflammation is associated with abnormal myoelectrical activity (Aube et al. 1999; Banach et al. 2001). Analysing the changes occurring in the spontaneous myoelectrical activity and tissue conductivity of the normal and inflammatory-changed mammary glands can be a new method of diagnosing the inflammatory process of the mammary gland. Quick tests showing the changes in the milk content during inflammatory process are now used in the diagnostics of mastitis. One of the most widely used tests is CMT - California Mastitis Test (Shitandi and Kihumbu 2004). In this study a pioneering attempt was made to confirm the usefulness of registering both the spontaneous myoelectrical activity and the changes in udder resistance in the diagnosis of mastitis.

Animals

\section{Materials and Methods}

The study was carried out on a group of 14 highly productive dairy cows of the Holstein-Friesian breed on the School Agricultural Farm in Zemplinska Teplica (Slovakia). The cows in their $3^{\text {rd }}-4^{\text {th }}$ lactation used in the study were kept in free box housing system and milked in DeLaval parlour, tandem $2 \times 4$ (Tumba, Sweden) twice a day.

Address for correspondence:

Albert Czerski

Department of Biostructure and Animal Physiology

Institute of Animal Physiology

Wroclaw University of Environmental and Life Sciences

Ul. Norwida 31, 50-375 Wrocław, Poland 
Before the recording of the udder myoelectrical activity, a sample of milk from each udder's quarter was collected in a sterile way for examination to rule out bacterial infection and inflammation. Only the animals qualified in the milk test as suffering from clinical mastitis, acute or subacute $(n=7)$, were subsequently used for the clinical group. Cows qualified as healthy $(\mathrm{n}=7)$ were used as the control group.

\section{Methods of udder examination and milk analysis}

Clinical changes in the udder were diagnosed by the presence of observable signs of inflammation, such as swelling, heat, pain or redness, and by the presence of clots and flakes in the milk, or by its abnormal colour or consistency. Milk samples from all 14 cows were examined microbiologically focusing on isolation and identification of pathogens such as Staphylococcus spp. and Streptococcus spp.

California Mastitis Test (CMT) was performed, using equal volumes of milk and alkyl-aryl-sulphate, and was evaluated as: 1) negative (-), not infected, healthy quarter, no thickening of the mixture; 2$)$ trace $( \pm)$, possible infection, slight thickening of the mixture; 3 ) weak positive $(+)$, infected, distinct thickening of the mixture but no tendency to form gel; 4) positive on $(++),(+++)$ CMT score.

According to clinical examination of the udder and results of CMT (Jackson and Cockcroft 2002), the animals were divided into two groups. Group 1: the clinical group, that included cows with clinical changes in the mammary gland, with positive CMT - more than $(+++)$ score, and with positive bacteriological diagnosis (samples with more than 5 colonies of isolated bacteria). Group 2: the control group, without clinical changes, with negative or trace $( \pm$ ) CMT, and negative bacteriological examination.

Quarter milk samples were collected by hand-stripping into $25 \mathrm{ml}$ tubes with stabilized reagent $(1 \mathrm{mg} / 1 \mathrm{ml}$ potassium dichromate). After mixing, samples were transported at the temperature from $1{ }^{\circ} \mathrm{C}$ to $10{ }^{\circ} \mathrm{C}$ to the laboratory, and examined within the next $24 \mathrm{~h}$. Quarter milk samples for microbiological examination were collected from each observed cow as follows: after drawing and evaluation of the first 6 squirts of milk, the teat ends were disinfected with cotton wool dipped in $70 \%$ ethyl alcohol. Subsequently, milk was collected aseptically from the teats directly into sterile $10 \mathrm{ml}$ tubes. The tubes were held at an angle of approximately $45^{\circ}$. The samples were kept at $4-8{ }^{\circ} \mathrm{C}$ during transportation to the laboratory.

\section{Staphylococcus spp. detection and identification}

Milk samples $(0.05 \mathrm{ml})$ were inoculated onto blood agar (Oxoid, UK) and cultivated at $36{ }^{\circ} \mathrm{C}$ for $24 \mathrm{~h}$. Based on the colony morphology, Staphylococcus spp. bacteria were selected for the tube coagulase test (Staphylo PK, ImunaPharm, Šarišské Michal'any, Slovakia). Suspected colonies were isolated again on blood agar, cultivated at $36{ }^{\circ} \mathrm{C}$ for $24 \mathrm{~h}$ and identified biochemically using the STAPHYtest 24, STREPTOtest 24 and identification software TNW Pro 7.5 (Erba Lachema, Brno, Czech Republic). In case of doubtful results, the respective strains were sent to the Czech Strain Collection of Microorganisms in Brno for more accurate identification using specific biochemical tests or molecular methods.

\section{The recording of udder myoelectrical activity}

The recording of udder myoelectrical activity was carried out using PowerLab/ 800 (ADInstruments, New Zeland) connected to the computer. The Chart v4.1 (ADInstruments) software was used to write, read and analyse the data. In each of the three channels the filters were set as follows: high cut-off filter on $35 \mathrm{~Hz}$ and low cut-off filter on $0.3 \mathrm{~Hz}$ (Troedsson et al. 1993a; Troedsson et al. 1993b; Haluska et al. 1987; Janszen et al. 1993). The signal was enhanced with BioAmp (ADInstruments, Melbourne, Australia). The sampling rate was set to 40 samples per second. The myoelectrical activity was registered using bipolar electrodes separately in each quarter. The electrodes used for ECG (Bio Lead-Lok B, catalogue number: R-LFO-500) were adapted for the study. One electrode was placed at the udder's base; the other electrode was placed right at the base of the teat. The electrical activity of the four quarters of the udder was recorded simultaneously using four bipolar electrodes. The electrodes were covered with the ECG gel to provide a better contact between the electrodes and the tissue.

A 15-min udder myoelectrical activity recording was conducted to develop the patterns of electrical activity. Subsequently, the udder was stimulated in order to verify the udder reaction to electrical current of constant voltage and intensity generated by the EMS (electrical muscle stimulator) designed for the study. A uniphasic waveform was employed in these studies. The mammary gland was electrically stimulated for $2 \mathrm{~min}$ at $33 \mathrm{~Hz}$. Pulse duration was $54 \mu \mathrm{s}(8 \mu \mathrm{s}$ ramp down duration). The output voltage was $25 \mathrm{~V}$ and output current $50 \mathrm{~mA}$ (measured for a resistance of $500 \mathrm{Ohm}$ ). All four quarters of the udder were stimulated in the following order: right front, right back, left front, and left back. The EMS electrodes were placed $3 \mathrm{~cm}$ from the electrodes used for registering the myoelectrical activity of the udder with one electrode at the udder's base and the second one right at the base of a teat.

Data analysis and statistical analysis of results

The obtained electromammograms were analysed off-line using Chart v4.1 software (ADInstruments) working under Windows 98OS. The value of myoelectrical index (Krishnamurti et al. 1982) and the number of spike potential groups per minute (Troedsson et al. 1993a; Troedsson et al. 1993b; Harding et al. 1982; Massmann et al. 1991) were calculated. Moreover, the mean duration of the spike potential group, the mean amplitude of the spike discharge, and the mean number of spike discharges in the spike potential group, were calculated to describe the patterns of the udder's myoelectrical activity. In case of electrical stimulation, the reaction time and the amplitude of electrical current flow $(\mu \mathrm{V})$ were measured. The results were shown as mean values $\pm \operatorname{standard}$ deviation $(\vec{x} \pm \mathrm{SD})$. 


\section{Results}

Bacteriological examination of milk

Animals from the control group showed no pathological changes in the CMT of milk from all four quarters (CMT negative) and no pathogenic bacteria growth in the milk bacteriological examination.

Animals from the clinical group showed positive results of the CMT, from $(++)$ to $(++++)$, in all four quarters of the udder. Pathological changes in the clinical examination of the udder were diverse and indicated mastitis. They included changes in the milk such as change of

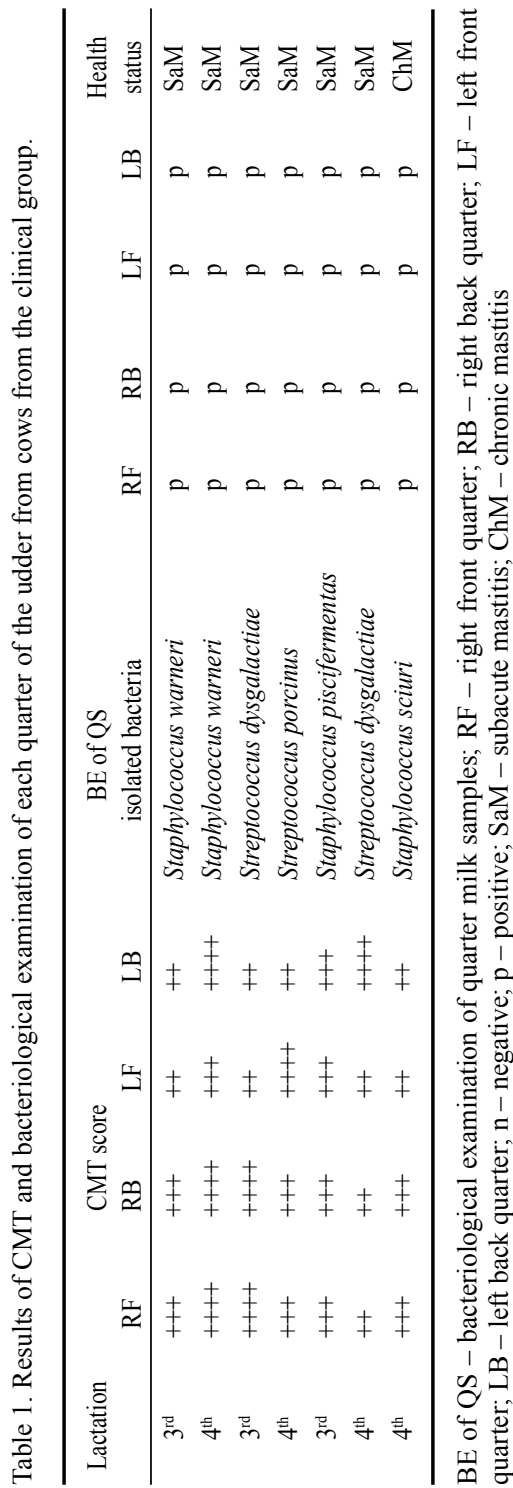
smell, consistency and colour, and/or changes in the mammary gland such as redness and swelling of the udder. Bacteriological examination showed pathogenic bacteria growth in all four quarters of the udder. Table 1 shows the results of the CMT and bacteriological examination of each quarter of the udder of cows from the clinical group.

\section{Patterns of myoelectrical activity}

The conducted experiment showed that a mammary gland considered as mastitis-free in cows during lactation shows a myoelectrical activity characterized by the occurrence of spike potential groups with the frequency of $2.33 \pm$ $0.6 / \mathrm{min}$. The mean duration of the spike potential group was $8.12 \pm 1.68 \mathrm{~s}$. The mean amplitude of discharge was $457 \pm 147 \mu \mathrm{V}$, while the mean count of spike discharges in a group was 3.86 \pm 0.97 . The myoelectrical index was $\mathrm{MI}=31 \pm$ $4 \%$. There were no significant differences in the myoelectrical activity between the four quarters of the udder (Fig. 1). It is also confirmed by previous results (Czerski et al. 2013).

Stimulation of the udder in cows confirmed as mastitis-free using EMS caused the appearance of the electrical current flow of the mean amplitude of $8.75 \pm 1.93 \mathrm{mV}$. After turning on the EMS, the spike potentials emerged immediately and faded instantly after turning the device off without causing a reaction of the udder tissue to the electrical current flow. Fig. 2 shows a recording of an udder quarter stimulation using the EMS $(9 \mathrm{mV})$ in a cow from the mastitis-free group.

The mammary gland of cows considered as suffering from mastitis during lactation showed a myoelectrical activity characterized by the occurrence of spike potential groups with the frequency of $2.6 \pm 0.84 / \mathrm{min}$. The mean duration of the spike potential group was $5.56 \pm 1.58 \mathrm{~s}$. The mean amplitude of discharge was $2470 \pm$ $578 \mu \mathrm{V}$, while the mean count of spike discharges in a group was $3.38 \pm 1$. The myoelectrical index 


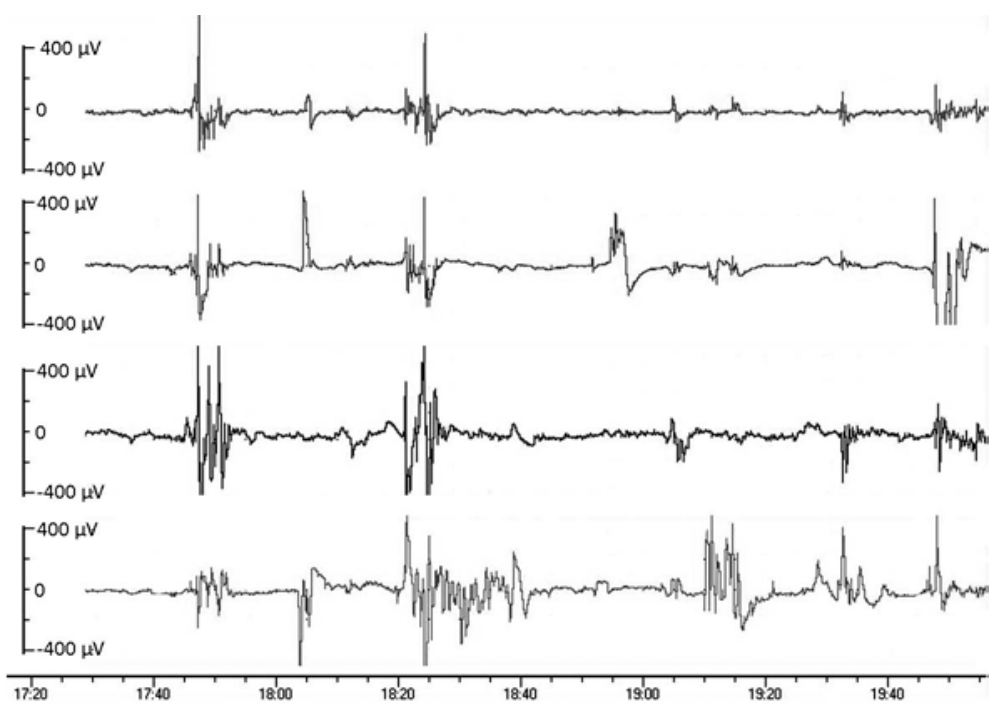

Fig.1. Myoelectrical activity of a highly productive dairy cow's udder from the control group. From the top: right front, left front, right back and left back quarter of the udder. The discharge amplitude $[\mu \mathrm{V}]$ and time (in min) is shown in the recording.

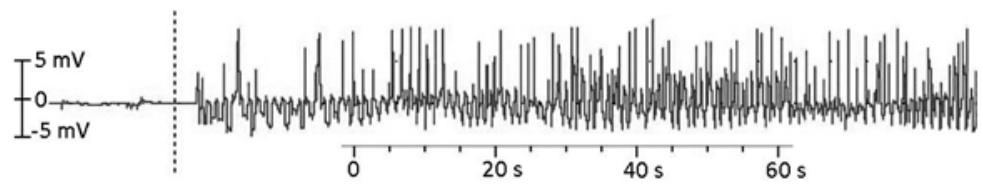

Fig. 2. Stimulation of the left back quarter of the udder of a cow considered as mastitis-free using the EMS (electrical muscle stimulation).

was $\mathrm{MI}=35 \pm 6 \%$. There were no significant differences in the myoelectrical activity between the four quarters of the udder. Fig. 3 shows a recording of the myoelectrical activity of the mammary gland of a cow considered as suffering from mastitis.

The udder stimulation using EMS (electrical muscle stimulator) in cows considered as suffering from mastitis caused the flow of electrical current of the mean amplitude of $4 \pm$ $1.53 \mathrm{mV}$. After turning on the EMS, the spike potentials emerged immediately and faded instantly after turning the device off without causing any reaction of the udder tissue to the flowing electrical current. Fig. 4 shows a recording of stimulation of udder quarter using the EMS in a cow considered as mastitis-free (upper recording) and in a cow considered as suffering from mastitis (lower recording).

\section{Discussion}

The spontaneous electrical activity of the mammary gland of the mean amplitude of $457 \pm 147 \mu \mathrm{V}$ can be recorded from the surface of the udder. The groups of action potentials emerge with the frequency of $2.33 \pm 0.6 / \mathrm{min}$. It confirms our previous study on spontaneous electrical activity of the mammary gland and on the stimulating effect of manual and mechanical milking on this activity (Czerski et al. 2013). 

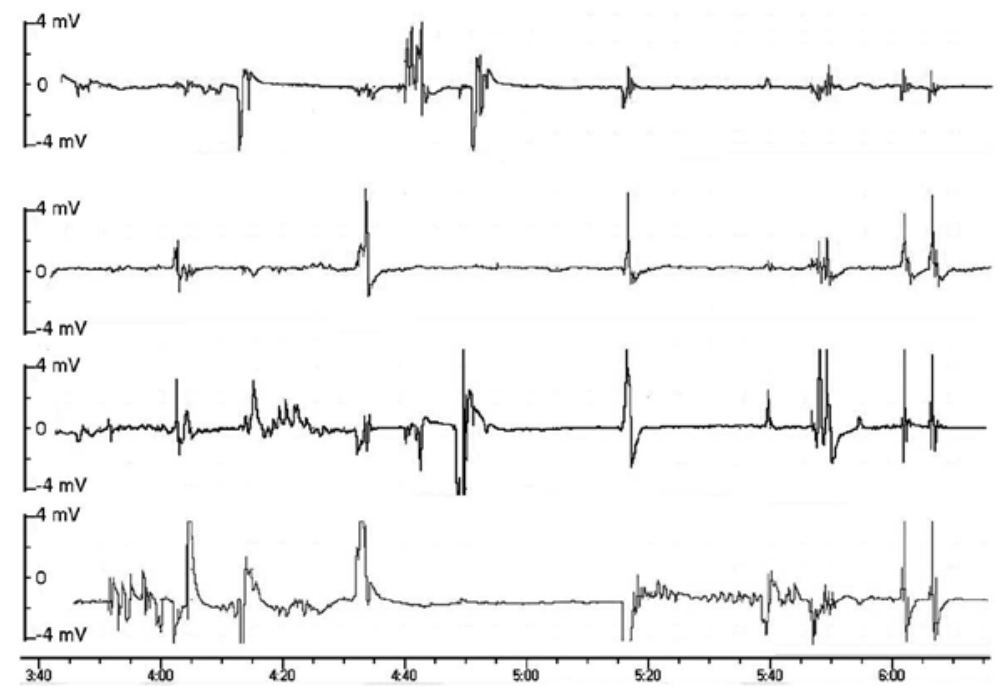

Fig. 3. Myoelectrical activity of the udder of a highly productive dairy cow considered as suffering from mastitis. From the top: right front, left front, right back and left back quarter of the udder. The discharge amplitude [ $\mu \mathrm{V}]$ and time (in min) is shown in the recording.

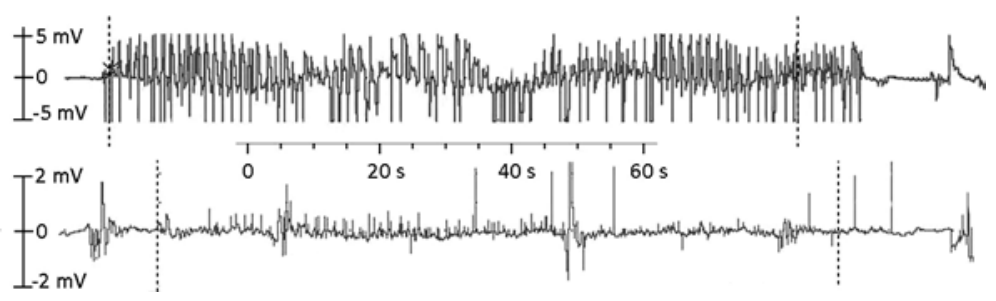

Fig. 4. Stimulation of the mammary gland using the EMS signal amplitude of $5 \mathrm{mV}$. The upper recording shows stimulation of the right back quarter which showed the CMT result as (-). The lower recording shows stimulation of the left back quarter which showed the CMT result as $(++++)$.

In case of the registration from the surface it has to be taken into consideration that the recorded potential is a resultant of the sum of potentials occurring in the vicinity of the electrode, and in the case of using the bipolar electrodes it is a resultant of the potential between the electrodes. The differences in tissue resistance between blood, muscle, adipose tissues and glandular tissue are used in diagnostics (Karpov et al. 1997). Our study shows a significant difference in the spontaneous electrical activity of the normal and inflammatory-changed cow's mammary gland. In the abnormal glandular tissue the mean amplitude of registered spike potentials showed an increase of $540 \%$ compared to the amplitude in normal tissue $(2479 \mu \mathrm{V}$ compared to $457 \mu \mathrm{V} ; P \leq 0.005)$. The mean duration of spike potential group was also changed. The decrease of $31 \%(P \leq 0.005)$ compared to the normal glandular tissue was noted. As shown in many studies, epithelial glandular cells forming the mammary gland do not show action potentials (Loewenstein and Penn 1967; Adams et al. 1982). Only the stimulation of those cells, for example the hormonal stimulation (with epidermal growth factor or insulin), causes a spontaneous 
hyperpolarization, which results in the presence of potentials that can be recorded. This fact was observed in the glandular epithelial cells in mice (Enomoto et al. 1986). It is possible that the reaction is caused by activation of calcium-activated potassium channels (Williams 1981), or that the hyperpolarizing potential originates from activation of the sodium-potassium pump (Enomoto et al. 1986).

An increase in the amplitude of the spontaneous myoelectrical activity during inflammation was observed. It is probably caused by mediators of the inflammatory process released from leukocytes, irritating both the glandular epithelium cells and the smooth muscle tissue (Enomoto et al. 1986). Also the disturbances in microcirculation in the mammary gland and the oedema of the gland have undoubted influence. In our study the change in resistance of the inflammatory-changed gland compared to the normal one was also noted. During the electrical current flow through the glandular tissue, a mean decrease of $54.28 \%$ in the current voltage in the mastitis-changed gland compared to healthy tissue was noted. This change in the current voltage is an evidence of a considerable increase in resistance of the inflammatory-changed tissue. The impedance of glandular tissue is relatively small $(25 \mathrm{M} \Omega$ ) compared to other tissues, for example the chromaffin endocrineactive cells in the adrenal glands, where the impedance amounts to approximately $430 \mathrm{M} \Omega$ (Brandt et al. 1976).

Both the measurement of the spontaneous myoelectrical activity (the increase in the amplitude of spike potentials in the inflammatory-changed gland) and the measurement of the decline in the voltage of the electrical current passed through the gland can be an alternative to the CMT test because of their simplicity, velocity and inexpensiveness (the device can be used for years). Nonetheless, the device has to be tested on a larger number of animals for better verification of its diagnostic effectiveness.

\section{Acknowledgements}

This work was supported by the project APVV-0629-07 and by the project APVV-0679-10.

\section{References}

Adams PR, Constanti A, Brown DA, Clark RB 1982: Intracellular $\mathrm{Ca}^{2+}$ activates a fast voltage sensitive $\mathrm{K}^{+}$ current in vertebrate sympathetic neurones. Nature 296: 746-749

Aube AC, Cherbut C, Barbier M, Xing JH, Roze C, Galmiche JP 1999: Altered myoelectrical activity in noninflamed ileum of rats with colitis induced by trinitrobenzene sulphonic acid. Neurogastroenterol Motil 11: $55-62$

Banach T, Ciećko-Michalska I, Cibor D, Szulewski P, Bogdał J, Thor PJ 2001: Myoelectric activity of the stomach and esophageal $\mathrm{pH}$ changes in reflux disease. Folia Med Cracov 42: 53-61

Brandt BL, Hagiwara S, Kidokoro Y, Miyazaki S 1976: Action potentials in the rat chromaffin cell and effects of acetylcholine. J Physiol 263: 417-439

Czerski A, Vasil' M, Elečko J, Farkašová Z, Zigo F, Zawadzki W, Dudko P, Gnus J, Janeczek M, Chrószcz A 2013: The patterns of myoelectrical activity and reaction for teat stimulation recorded in highly productive dairy cows' udders. Acta Vet Brno 82: 323-329

Enomoto K, Cossu MF, Edwards C, Oka T 1986: Induction of distinct types of spontaneous electrical activities in mammary epithelial cells by epidermal growth factor and insulin. Proc Natl Acad Sci USA 83: 4754-4758

Haluska GJ, Lowe JE, Currie WB 1987: Electromyographic properties of the myometrium correlated with endocrinology of the pre-partum and post-partum periods and parturition in pony mares. J Reprod Fert Suppl 35: $553-564$

Harding R, Poore ER, Bailey A, Thorburn GD, Jansen CAM, Nathanielsz PW 1982: Electromyographic activity of the nonpregnant and pregnant sheep uterus. Am. J Gynecol 142: 448-457

Jackson P, Cockcroft P 2002: Clinical Examination of Farm Animals. Blackwell Science Ltd, Oxford, UK, pp. 154-166

Janszen BPM, Bevers MM, Ravenshorst MM, van der Weijden GC, Dieleman SJ, Taverne MAM 1993: Relationship between prostaglandin-induced luteoysis and temporary inhibition of myometrial activity in late pregnant cows with ear implants containing progestagen. J Reprod. Fert 97: 457-461

Karpov A, Trokhanova O, Cherepenin V, Korjenevsky A 1997: Electrical impedance anatomy of the mammary gland. Bull Russ Acad. Med Sci 4: 52-56 
Krishnamurti CR, Kitts DD, Kitts WD, Tompkins JG 1982: Myoelectrical changes in the uterus of the sheep around parturition. J Reprod Fert 64: 59-67

Loewenstein WR, Penn RD 1967: Intercellular communication and tissue growth. II. Tissue regeneration. J Cell Biol 33: 235-242

McCaig CD, Song B, Rajnicek AM 2009: Electrical dimensions in cell science. J Cell Sci 122: 4267-4276

McCaig CD, Rajnicek AM, Song B, Zhao M 2005: Controlling cell behavior electrically: current views and future potential. Physiol Rev 85: 943-978

Massmann GM, Figueroa JP, Nathamielsz PW 1991: Futher characterization of electromyographic activity of the myometrium and mesometrium in nonpregnant sheep under estrogen supplementation. Biol. Reprod 45: 605-610

Shitandi A, Kihumbu G 2004: Assessment of the California mastitis test usage in smallholder dairy herds. J Vet Sci 5: 5-9

Troedsson MHT, Wiström AOG, Liu IKM, Ing M, Pascoe J, Thumond M 1993a: Registration of myometrial activity using multiple site electromyography in cyclic mares. J Reprod Fertil 99: 299-306

Troedsson MHT, Liu IKM, Ing M, Pascoe J, Thumond M 1993b: Multiple site electromyography recordings of uterine activity following an intrauterine bacterial challenge in mares susceptible and resistant to chronic uterine infection. J Reprod Fert 99: 307-313

Williams JA 1981: Electrical correlates of secretion in endocrine and exocrine cells. Fed Proc 40: 128-134 